\title{
Design and implementation of a smart elderly positioning management system based on wireless communication network
}

\author{
Tiantian Yu ${ }^{1}$ and Ruping Wang ${ }^{2^{*}}$
}

\author{
${ }^{*}$ Correspondence: \\ wrpqyi@163.com \\ ${ }^{2}$ School of Management, \\ China West Normal \\ University, Nanchong 637002, \\ Sichuan, China \\ Full list of author information \\ is available at the end of the \\ article
}

\begin{abstract}
Wireless communication refers to long-distance transmission communication between multiple nodes without propagation through conductors or cables, and wireless communication can be carried out by radio and electromagnetic waves, etc. Judging from the current situation, the home space positioning design of the medical and elderly care communities is not perfect, which affects the traditional home care. Wireless communication can give wisdom, coordination, and development space in the smart elderly care space positioning design, allowing the elderly to interact, contact, and know their precise location and behavior. This article mainly studies the design and implementation of smart pension space positioning under BIM technology. This paper introduces the frontier of Internet-of-things technology and the theory of sensor network topology control. It uses basic loT technology to implement the "point, line, and surface" combination of personnel placement algorithms, sensor network communication protocols, topology checks, security models, sensor network wireless communication units, and wireless communication technology. The basic technology and communication technology of personnel deployment based on BIM technology are introduced, the development strategy of wireless communications node is studied, the installation of equipment radio personnel and communication equipment is designed, and the system management platform for the design and development of staff placement in pension institutions is provided. The Web site's information service management, standardized procedures, optimized services, provision of information, intelligent management, and pension services. The experimental results of this paper show that the smart pension space positioning under the BIM technology solves the management loopholes in nursing homes, shortage of nursing staff, inefficiency, lack of services, and family conflicts. It improves the efficiency of the elderly by $25 \%$ and the safety index by $23-27 \%$. The development of wireless communication technology promotes the development of intelligent pension space. It will be an important future development direction for the smart community pension.
\end{abstract}

Keywords: BIM technology, Smart elderly care, Spatial positioning, System design, Population aging author(s) and the source, provide a link to the Creative Commons licence, and indicate if changes were made. The images or other third party material in this article are included in the article's Creative Commons licence, unless indicated otherwise in a credit line to the material. If material is not included in the article's Creative Commons licence and your intended use is not permitted by statutory regulation or exceeds the permitted use, you will need to obtain permission directly from the copyright holder. To view a copy of this licence, visit http:// creativecommons.org/licenses/by/4.0/. 


\section{Introduction}

\subsection{Background and significance}

The problem of China's aging population is becoming increasingly serious. According to the 2013 China Economic Growth Survey, China's elderly population is expected to reach 202 million in 2013. By the end of 2014, the elderly population will continue to increase. For a long time, family pension has been the main form of China's pension model. However, with China's transition to economic society and the long-term implementation of the basic national policy for family planning, family-scale photomicrography has become the main trend, and the family structure of children is becoming more and more common. Therefore, the number of empty nest families is increasing. The number of old-age care institutions is limited, the number of transferable elderly people is much lower than the social needs, the level of information is low, the effectiveness of case management and personnel management is low, the level of modernization of information services is low, professional equipment is lacking, and the ability to monitor vulnerable elderly groups is seriously inadequate. Elderly disabled people and other aspects lack reasonable and effective means to meet the health needs of the elderly. This not only makes the management and service quality of pension institutions uncertain, but also brings many possible problems to the society.

BIM technology is used as an application tool for data design, construction, and management to improve production efficiency. At the same time, it plays an important role in saving machinery costs and shortening the construction period. It has broad application prospects in mechanical engineering. If you want to overcome the competition of industrial engineering bridges on a curve, then it can promote its in-depth use of BIM technology. The implementation of BIM technology also includes management changes, which can exchange information throughout the entire life cycle of the building to support the integration of design, construction, and management. It is of great significance to engineering construction and follow-up operation management and helps to promote the transformation of production methods in the construction industry.

This paper designs an intelligent pension management system based on BIM technology, with information technology applied to pension institutions to improve the efficiency of staff management and transaction management in pension institutions, reduce labor costs, and effectively alleviate the "large gap of nursing staff." The aim is to provide elderly people with a safe, comfortable, warm, and multi-functional elderly care space, as a part of the development of a smart city, and to promote the healthy development of China's elderly care industry. Based on this, it is particularly important to analyze the necessity and application strategy of BIM technology in order to improve the quality of smart design in the retirement space.

\subsection{Development status of BIM technology at home and abroad}

China began to introduce the concept of BIM in 2001. In 2008, China successfully applied BIM technology to the design and construction of Shanghai Tower, which enabled this technology to develop and spread rapidly in China.

Although the implementation of China's BIM technology started slowly and the starting line is relatively low, the development momentum in the past decade has been quite rapid. In 2005, Zhang Jianping combined the IFC format standard and 4D 
model research to establish a $4 \mathrm{D}$ project management system for project construction. In 2008, Hu Zhenzhong proposed a BIM-based bridge full life cycle management framework. In 2001, Huazhong University of Science and Technology independently established China's first BIM research and technology institute. In 2012, Niu Bosheng introduced BIM technology into project schedule management. In 2013, 8 units including the Railway Company and the Railway Research Institute jointly established the China Railway BIM Alliance. In 2014, Geely University of Architecture became the first university in China to incorporate BIM into the curriculum system and began to recruit new students, which means that BIM has become truly universal knowledge. In the same year, Yang Yongyi and others used the Dassault platform for the first time to build a complete BIM model bridge. In 2017, Qingdao Mahang University of Science and Technology used the Chongli Railway Zhaochuan Super Large Bridge Project to apply BIM technology to simulate stress and perform the bridge torsion process. BIM has created a boom in domestic manufacturing. The Wenchuan Earthquake Memorial Hall, Shanghai Times Financial Center, National Grand Stage, etc., are all examples of successful implementation of BIM technology in Chinese manufacturing.

The mathematical model formula of BIM is as follows:

$$
\mathrm{BIM}=\sum_{r=1}^{k}[\mathrm{CDM}] i j r \cdots(i=1,2, \ldots, n ; j=1,2, \ldots, m)=\sum[\text { Excel }]
$$

where $(I, J, R)$ is the ID corresponding to the component coordinates $(x, y, z)$ and CDM is the mathematical structure of component metadata.

3D BIM model:

$$
3 \mathrm{DBIM}=(\mathrm{IFC}+\mathrm{IEF}) .
$$

In 2018, the implementation of foreign BIM technology continued to develop rapidly. For example, the development trend of the USA, the UK, Singapore, and other countries and regions is very good. The commercialization and promotion of BIM technology were initially achieved by promoting industry and commerce. Among the developed Asian countries, South Korea and Japan are representative, and their development is worthy of reference and research by our country.

It must be said that the representative of BIM is the USA, and the USA can be regarded as the world's first and most widely implemented national BIM technology. Since 2003, the USA has launched a national BIM project aimed at increasing visibility, informatization, and technology level in the field of construction engineering. The implementation goal of this project is to provide strategic advice and technical support for the engineering project; since 2007, it has been determined that all projects to be auctioned must undergo spatial planning and final demonstration of concepts through BIM. From 2013 to 2016, the proportion of US construction contractors applying BIM far exceeded half, reaching the upper limit of $80.1 \%$. Especially in North America, BIM accounts for a relatively high proportion in manufacturing. In 2006, the US Military Machinery Corps, a subsidiary of the US Federal Agency, formulated and released a BIM roadmap from 2006 to 2020. It uses BIM technology and 
expressed its commitment to use BIM technology for all military-related projects in the near future.

\subsection{Related work}

Akinade $\mathrm{O} O \mathrm{O}$ has fully demonstrated the need to use building information models to minimize construction waste, but most existing CDW management tools still lack BIM capabilities. Therefore, he assessed the expectations of stakeholders on how BIM can be used for CDW management. After reviewing the existing literature to assess the limitations of existing CDW management tools, he conducted qualitative focus group interviews with professionals familiar with the use of BIM to understand their expectations of using BIM for CDW management. But he did not make a more in-depth study, so that the conclusions reached are not very accurate [1]. In his research on smart community pension services, Hao $\mathrm{C}$ found that due to lack of information and the acceptance of smart products by the elderly, the problems encountered in the promotion of smart pensions cannot be solved in the short term. He put forward research ideas based on the cognitive characteristics and demand prediction of specific populations. It focuses on the elderly care needs of the population born in the 1960s or 1970s and provides support for the solution of intelligent elderly care services during peak periods. However, because the study population is only 10 years old, the study results are not very accurate [2]. Hoque J demonstrated a concept in which the antibacterial and cytotoxic activity of cationic small molecules is regulated by the spatial positioning of the hydrophobic part while keeping the positive charge constant. Compared with the more hydrophobic molecules from the positive centers (MIC $=1-4 \mu \mathrm{g} / \mathrm{mL}$ and $\mathrm{HC} 50=60-65 \mu \mathrm{g} / \mathrm{mL}$ ), the more hydrophobic molecules between the two centers show similar antibacterial activity. But the toxicity to human red blood cells is greatly reduced (MIC $=1-4 \mu \mathrm{g} / \mathrm{mL}$, $\mathrm{HC} 50=805-1242 \mu \mathrm{g} / \mathrm{mL}$ ). However, the toxicity he calculated is only a rough estimate, not an accurate figure [3].

\subsection{Main content}

This paper mainly studies the realization of the smart pension space positioning system under BIM technology and the application of BIM in smart space pension management. The main work contents are as follows:

1. Tell about the design and implementation of a smart pension space positioning system based on BIM technology, and make a series of analysis of the safety of the elderly to ensure that they can be located and monitored at any time and any place.

2. Enter the relevant theories of BIM and smart space pensions, analyze the current situation and evolution of China's population aging, and solve the pension problem brought about by population aging. The PEST method is used to analyze and compare the advantages and disadvantages of the current three pension insurance methods in China and verify the necessity of the intelligentized pension system in our country.

3. On the basis of summarizing Maslow's hierarchy theory, social tolerance theory and analysis of the normal and psychological characteristics of the elderly, establish an evaluation system of factors that affect the quality of the elderly in smart elderly care 
communities. Instead, the structural entropy weight method is used to determine the influence weight of each factor.

4. According to the factors affecting the smart community, divide the smart community management unit, establish a general smart community management platform based on BIM, and implement BIM in the smart community, combining the BIM model with the software; Pathfinder evacuated in the community. The activity center performs safety evacuation simulation for the elderly and optimizes its layout. According to the simulation results, room operation, flow control, and use of the activity center space are performed [4].

\section{Method/experiment}

The BIM technology studied in this paper is based on a three-dimensional digital technology, an engineering data model that integrates various pieces of relevant information of construction projects, and is a digital expression of the physical and functional characteristics of engineering facilities. Taking BIM technology as the research background and taking the elderly as the research object, the spatial design and spatial positioning of the residential houses are carried out.

This article adopts wireless radio frequency positioning technology for the design of the positioning system, which is a positioning technology consisting of three parts: a radio frequency tag, a radio frequency reader, and a software system, which transmits information through radio frequency signals. And the function of the positioning system is judged by the evacuation of the elderly in the retirement space, and the effect of the space design is judged by the length of the evacuation time [5].

This article is designed for the seniors' residence on the second floor, the first floor is the hall, dedicated to eating, the second floor is the gymnasium, used for sports and fitness, and the activity room is used for recreational activities. The materials include dining table, table tennis table, and badminton court. And intelligent entropy space positioning structure entropy weight method is used to calculate "cognitive blindness," and the formula is given as follows:

$$
R_{j}=\left[\left(\max \left(d_{1 j}, d_{2 j}, \ldots, d_{k j}\right)+\min \left(d_{1 j}, d_{2 j}, \ldots, d_{k j}\right)\right)\right] / 2 \mid .
$$

\section{BIM technology smart pension space positioning method}

\subsection{D visual management based on BIM smart community spatial positioning}

\section{3D visual management of smart community}

Compared with the previous three-dimensional visualization of BIM technology, the information of each component is more intuitively expressed by lines. Moreover, the three-dimensional model of BIM is generated automatically by the information contained in the components, and the components are interactive and feedback. BIM technology can make the community building information accurate to the component level and can show the whole community environment with three-dimensional model, which makes the data more accurately express the reality. This is BIM software 
compared with two-dimensional drawings, CAD. The software has its unique advantages, which is very helpful for us to locate the danger source and the people in need of rescue in case of emergency [6].

\section{Information diversification}

BIM model contains the detailed information of the building. When the component is created, all the physical information, chemical information, and purchase information of the component will be generated at the same time, and the material schedule can be extracted at any time, including the schedule of structural columns, walls, beams, plates, etc., and including the specific properties of material strength and consumption.

\section{Simulation}

BIM technology in community operation and maintenance management can be based on 4D (3D + time) sunshine analysis, acoustic environment simulation, collision inspection, personnel emergency evacuation simulation, energy saving analysis, etc.; based on 5D $(3 \mathrm{D}+$ time + cost $)$ construction dynamic cost simulation. For example, BIM can be used for collision inspection and virtual rehearsal of construction scheme of equipment and pipeline to be installed during decoration and pipeline equipment maintenance, which can reduce the accident rate and change during construction; BIM can be used for demonstration of residents' safe evacuation, which can not only reduce the manpower and financial resources of evacuation exercise, but also reduce the occurrence of accidents in case of emergency.

BIM software can also simulate the construction progress, import the established BIM model and the project construction organization plan into the Autodesk NavisWorks software timeliner to simulate the construction organization, simulate the construction process in advance, and find the work conflict and idle time in the construction organization plan, which is helpful to save the construction period and reduce the construction cost [7].

4. Support multiple data transmission formats for information integration and sharing

BIM software implements the international IFC Standard industry foundation claim. The Revit series software of Autodesk company supports CAD graphics format (DWG DXF $\backslash$ DGN $\backslash S A T$ ), FBX format, gbxml format, ODBC database format (open database activation), Excel, video recording and animation format, etc.; in addition, Revit also provides API secondary development interface, and users can use $\mathrm{C}+$ according to their own needs for the project VB. NET Language and so on.

\subsection{Special needs of the elderly for the community environment}

\section{Physiological characteristics of the elderly}


1. Physical motor function

Although the physical function of the elderly aged 65-75 years gradually declines, they can basically take care of themselves. Once they are 75 years old, there will be certain obstacles in their activities, and they need to use crutches, wheelchairs, and other tools. After 85 years old, the elderly's physical function will accelerate decline, and they need continuous care.

\section{Perception and nervous system}

The vision of the elderly is decreased, the ability of color recognition is gradually reduced, the visual field is narrowed, and cataract is easy to occur; in terms of hearing, the elderly can reach 65 years. After the age of 65 years, the hearing is relatively weak, sometimes it needs to borrow hearing aids, and it is easy to be interfered by noisy sounds; it is relatively slow to distinguish things with touch, taste, and smell, mainly manifested in: the elderly are not sensitive to the peculiar smell in the air and slow to perceive the temperature and humidity. The decline of the nervous system in the elderly makes the elderly have poor memory, slow response, and poor ability to accept new things. This makes it easy for the elderly to get lost, walk away, or have accidents [8].

\section{Psychological characteristics of the elderly}

\section{Psychological changes brought about by changes in family roles}

Once the old man retires, he will feel empty and lonely when he changes from the dominant position of the head of the family to the role that needs to be supported by his children. With the increase of his age, his spouse or relatives will gradually die, which makes the old man feel more lonely and fear of death. With the increase of his age, he will gradually have no economic source, and it is difficult to accept the role of supporting his children. We will be sensitive to money.

\section{Psychological changes brought about by changes in social roles}

After retirement, many old people gradually become leisurely from a busy and regular life, which makes a lot of free time for the old people unable to have fun. The old people are easy to feel lonely, lost, and abandoned, which is extremely harmful to the physical and mental health of the old people. Many scholars believe that the real aging of the old people starts from the separation of social responsibility. In terms of interpersonal relationship, the old people leave their work team and environment, which makes the old people need to establish new interpersonal relationship in order not to be divorced from the society.

3. Psychological changes brought about by physiological changes 
The elderly's physical function is gradually declining, and there are certain obstacles in their activities. They need to use crutches, wheelchairs, and other tools to reduce their eyesight, which makes their range of activities smaller. In addition, their perception ability is weaker, and their hearing loss makes them reluctant to communicate with others, and they become blocked with information, emotional instability, and depression, which makes them gradually isolated from society, and their physiological functions. The changes brought to the mind in turn aggravate the aging of the elderly. With the growth of age, the memory and reaction ability of the elderly gradually decline. In order to avoid loss and accidents, it will also lead to that the elderly are not willing to go out and walk, the elderly lack of exercise, and the physical function will gradually decline.

3. The special needs of the elderly for the community environment

The physical and psychological characteristics of the elderly determine their way of life and mentality. When carrying out the elderly care management in the smart community, we should fully consider the elderly's needs for safety, environment, accessibility facilities, daily life, communication, self-realization, and constant attention, so as to ensure the normal, safe and healthy operation of the elderly's daily life and enrich their spiritual life, there are different solutions according to the different service needs of the elderly [9].

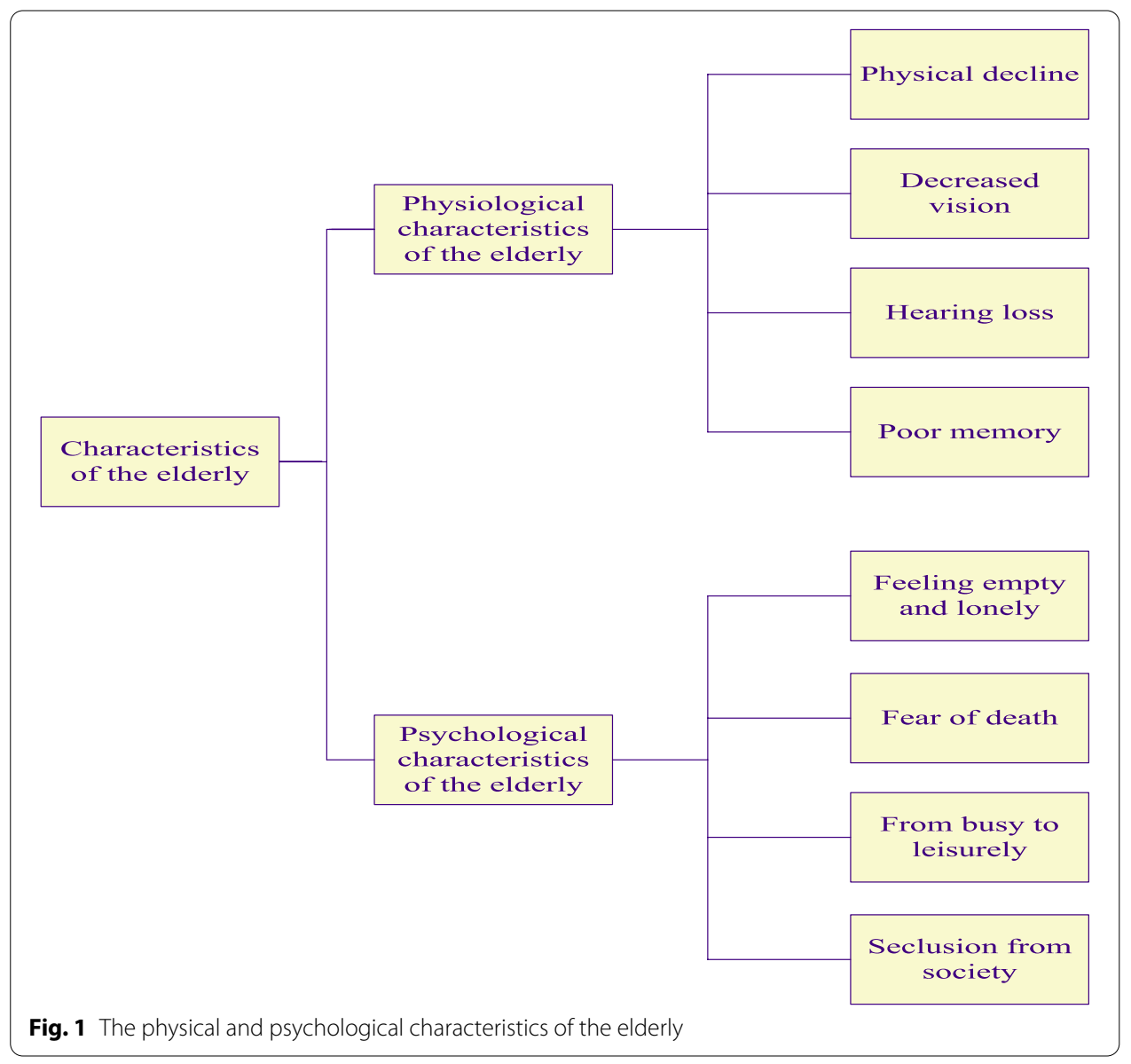


The physical and psychological characteristics of the elderly are shown in Fig. 1:

\subsection{The weight calculation of the entropy weight method of the smart pension space positioning structure}

The structural entropy weight method should go through three steps: expert scoring, blindness analysis, and normalization.

\section{Expert scoring}

Select a certain number of experts and apply the expert scoring method to sort the factors in a typical way.

\section{Blindness analysis}

After the standard classification of factors, some experts may be classified. Therefore, the deviation of expert ratings should be further elaborated. The entropy weight method should be used [10].

There are $\mathrm{k}$ experts for scoring, including $\mathrm{n}$ influencing factors, and the typical ranking matrix obtained is $X_{k n}, x_{i j}$ is the evaluation of the factor $\mathrm{j}$ by the expert $\mathrm{i}, x_{i j}$ takes any natural number from 1 to $\mathrm{n}$, that is, $1 \leq x_{i j} \leq n$, and $x_{i j}$ is a natural number.

The membership function that transforms the typical ranking is:

$$
y\left(x_{i j}\right)=-\lambda p n\left(x_{i j}\right) \ln \left(x_{i j}\right) .
$$

Let $p n\left(x_{i j}\right)=\frac{m-x_{i j}}{m-1}, \lambda=\frac{1}{\ln (m-1)}$, then:

$$
y\left(x_{i j}\right)=-\frac{1}{\ln (m-1)}\left(\frac{m-x_{i j}}{m-1}\right) \ln \left(\frac{m-x_{i j}}{m-1}\right) .
$$

Let $v\left(x_{i j}\right)=\frac{\ln \left(m-x_{i j}\right)}{\ln (m-1)}$, then:

$$
v\left(x_{i j}\right)=\frac{\ln \left(m-x_{i j}\right)}{\ln (m-1)}=1-\frac{y\left(x_{i j}\right)}{\frac{m-x_{i j}}{m-1}}, \quad i \leq k, j \leq n .
$$

Set the membership matrix to $D$, where $d_{i j}$ is equal to $v\left(x_{i j}\right)$. Assuming that $k$ experts have the same importance on the index $v_{j}$, the average recognition degree of $v_{j}$ is:

$$
d_{i j}=\left(d_{1 j}+d_{2 j}+d_{3 j}+\cdots+d_{n j}\right) / k .
$$

Expert uncertainty about $v_{j}$ caused by cognition is called "cognitive blindness" and is denoted as $R_{J}$, then:

$$
R_{j}=\left|\left[\left(\max \left(d_{1 j}, d_{2 j}, \ldots, d_{k j}\right)+\min \left(d_{1 j}, d_{2 j}, \ldots, d_{k j}\right)\right)\right] / 2\right| .
$$

Normalized normalization

Make: 


$$
w_{j}=z_{j} / \sum_{j=1}^{n} z_{j}
$$

Then, $W=\left\{w_{1}, w_{2}, \ldots, w_{j}\right\}$ is the weight set of index set $U=\left\{u_{1}, u_{2}, \ldots, u_{j}\right\}$.

\subsection{The quality evaluation of smart pension space is based on TOPSIS method}

TOPSIS [11] is a multi-attribute decision-making method. The principle of the method is to: first analyze the weight of each influencing factor, collect data for the influencing factor, form an initialization matrix for each plan, and standardize the initial matrix and then determine an ideal point. The scheme closest to the ideal point is the best scheme. This article uses TOPSIS to evaluate the impact of BIM smart community pension quality and analyzes the impact of BIM on smart community pension quality. The specific implementation steps of TOPSIS method are as follows:

1. Establish an initialization matrix $Y, y_{i}$ is the influence value of the evaluation $j$ factor of the item $i, i=1,2,3, \ldots, m, j=1,2,3, \ldots, n m$ projects, $n$ influencing factors.

2. Normalization of matrix standards.

Normalize the initial matrix $Y$ according to the following formula to obtain the matrix $Y^{\prime}, Y^{\prime}=\left(y_{i j}^{\prime}\right)_{m n}$, as follows:

$$
y_{i j}^{\prime}=\frac{y_{i j}}{\sqrt{\sum_{i=1}^{m} y_{i j}^{2}}}, \quad i=1,2,3, \ldots, m, \quad j=1,2,3, \ldots, n .
$$

\section{Determine the ideal point}

The key to TOPSIS is to find scientific and reasonable ideal points [12], where ideal points are divided into positive ideal points and negative ideal points. The methods for determining positive ideal points and negative ideal points are as follows [13]:

Get the ideal point vector: Positive ideal point vector is $\lambda^{+}=\left(\lambda_{1}^{+}, \lambda_{2}^{+}, \ldots, \lambda_{n}^{+}\right)$.

Negative ideal point vector is $\lambda^{-}=\left(\lambda_{1}^{-}, \lambda_{2}^{-}, \ldots, \lambda_{n}^{-}\right)$.

4. Calculate the distance from each item to the ideal point [14]

Distance to positive ideal point:

$$
M_{i}^{+}=\sqrt{\sum_{j=1}^{n} u_{j}\left(y_{i j}^{\prime}-\lambda_{j}^{+}\right)^{2}}, \quad i=1,2,3, \ldots, m, \quad j=1,2,3, \ldots, n .
$$

Distance to negative ideal point: 


$$
M_{i}^{-}=\sqrt{\sum_{j=1}^{n} u_{j}\left(y_{i j}^{\prime}-\lambda_{j}^{-}\right)^{2}}, \quad i=1,2,3, \ldots, m, \quad j=1,2,3, \ldots, n .
$$

Among them, the vector $\mathrm{u}$ is the proportion of various factors [15].

4. Calculate the relative closeness

$$
C_{i}=\frac{M_{i}^{-}}{M_{i}^{+}+M_{i}^{-}}, i=1,2,3, \ldots, m .
$$

\subsection{RFID spatial positioning method of intelligent pension RFID system}

RFID has been widely used in finance, logistics, transportation, environmental protection, urban management, and many other industries. This paper uses RFID to identify the spatial location. RFID technology needs to activate the system tag to open the positioning function. In the tag communication protocol module, only [16]

$$
V_{m d} \geq V_{\text {active }}
$$

That is, the induced voltage $V_{m d}$ provided by the reader should be large enough to be greater than or equal to the activation voltage of the tag chip before the tag can work. The propagation loss of RFID RF microwave in free space is as follows:

$$
\begin{aligned}
L_{b f} & =201 \mathrm{~g}\left(\frac{4 \pi d}{\lambda}\right) \mathrm{dB} \\
\text { Or } L_{b f} & =32.45+201 g f(\mathrm{MHz})+201 g d(\mathrm{Km}) \mathrm{dB} .
\end{aligned}
$$

Among them, $D$ is the propagation distance of radio wave, $f$ is the working frequency, and $\lambda$ is the working wavelength.

The relationship between frequency wavelength and light speed is as follows:

$$
c=\lambda * f .
$$

According to the electromagnetic induction theorem, the induced voltage of the label is as follows:

$$
V_{m d}=2 \pi f Q N A \mu_{0} H
$$

where $q$ is the quality factor of the tag circuit, $n$ is the number of tag coil turns, a is the tag coil area, $h$ is the magnetic field strength, and $F$ is the carrier frequency. Therefore, the induced electric field that can activate the tag can be obtained [17]

$$
H=V_{\text {imd }} /\left(2 \pi f Q N A \mu_{0}\right) \geq V_{\text {active }} /\left(2 \pi f Q N A \mu_{0}\right) .
$$

Then, there is a minimum label to activate the induced electric field as follows:

$$
H_{\text {min }}=V_{\text {active }} /\left(2 \pi f Q N A \mu_{0}\right) .
$$


According to the restriction conditions of international organizations on the transmitting power of RFID system, we can choose $f=13.56 \mathrm{MHz}, \mathrm{Hmin}=9 \mathrm{~dB} \mu$ a, and $\mathrm{DM}=10 \mathrm{~m}$, so we can get the maximum reader magnetic coupling torque

$$
m_{\mathrm{RLim}}=4 \pi \frac{\lambda^{2} d_{m}^{3}}{\sqrt{\lambda^{4}-\lambda^{2} d_{m}^{2}+d_{m}^{4}}} .
$$

Among them, $\lambda$ is the carrier wavelength.

The maximum emission current of RFID system reader can be obtained as follows:

$$
I_{\mathrm{RMax}}=\frac{m_{\mathrm{RLim}}}{N_{R} a b}
$$

where $\mathrm{N}_{\mathrm{R}}$ is the number of turns of reader antenna coil and a and $B$ are the sizes of reading antenna coil, i.e., length and width.

Under ideal conditions, the formula for RFID tag activation is as follows:

$$
H=I_{R} \frac{2 a b}{\pi \sqrt{4 d^{2}+a^{2}+b^{2}}}\left(\frac{1}{4 d^{2}+a^{2}}+\frac{1}{4 d^{2}+b^{2}}\right) .
$$

At this point, the magnetic field strength of the reader and tag is equal [18].

\section{Experiment of smart pension spatial positioning}

\subsection{Overall framework of community spatial positioning system}

The existence of social space is the continuation of the living and working conditions of the modern elderly before retirement. The elderly have a strong desire and growing differentiation for social interaction. Based on the special theme of the elderly, it provides a space for the elderly to realize their social needs through life, learning, entertainment, sports, and other activities. The elderly expand their social circle and establish a community. They realized their value and found a sense of participation, which also adapted to the development of society. The specific process is shown in Fig. 2.

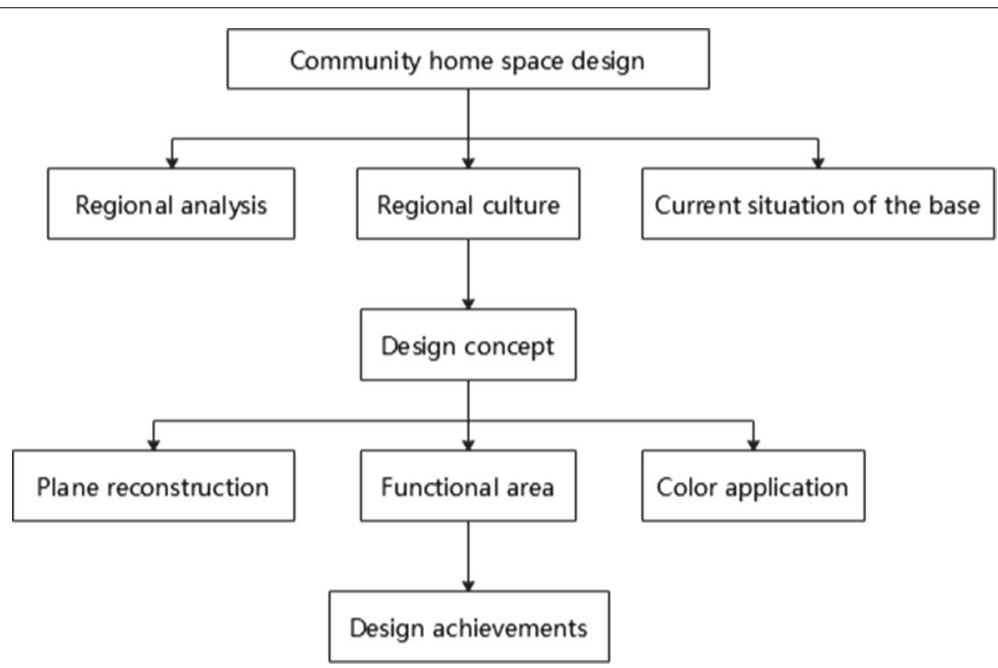

Fig. 2 Flowchart of community space design 


\subsection{Selection of social endowment space materials}

Interior decoration materials refer to the decoration materials of buildings connected with the walls, floors and tops of walls, as well as the decoration furniture and furniture materials that can be seen and touched indoors. For the physical and mental conditions of the elderly, the environment of the space used by the elderly activities should be constructed with more familiar, comfortable and humane interior decoration materials, and non-reflective materials should be selected in the sanatorium. The reflection of light is easy to make old people's eyes dazzled, disordered, or may cause temporary blindness, and easy to fall down accidentally. In addition, most of the elderly suffer from osteoporosis, which is easy to fall into mild conflict. In addition, the balance ability and response ability of the elderly are slow, so the soil surface where the elderly use the space must be made of antiskid and impact resistant materials, such as PVC sliding floor and wood floor commonly used in hospitals. Finally, the wall materials must be made of noise reduction and sound absorption materials to ensure the peace and comfort of aging environment [19].

When it comes to decorative materials, the use of color cannot be ignored. Different colors will have psychological and even physiological effects on people. The elderly are more sensitive and vulnerable than the young in psychological and physiological aspects. The internal color can even directly affect the life and psychological state of the elderly. When designing a comfortable and happy indoor environment for the elderly, the use of color is also crucial. Comfort, peace, and health are the majority of the elderly. Comfort, peace and health are the best aging environment pursued by most elderly people. According to the principle of aging adaptability of elderly care center in indoor environment, the design of space environment of elderly care center is based on many low-saturation color choices, such as milky white, beige, light gray, and green. Furniture accessories are mainly wood color. The atmosphere of lighting is transformed into a kind of temperature. The sweet and comfortable living environment is similar to the embrace of nature [20].

\subsection{Graphic design structure of community pension}

The living environment of the elderly is very important for them. Environmental factors will affect their mood and entertainment, so independent functional rooms are set up. The comprehensive activity room and hall on the first floor are usually used for playing cards, mahjong, and other entertainment. The education room on the second floor has set up training courses in the early stage of establishment, and occasionally, there are some knowledge lectures related to the elderly. The functional room configuration of the facilities can meet the needs of learning, entertainment, physical exercise, and social interaction. As the location proposed in the conceptual plan is the area where the elderly live in the community, the land area is relatively tight, so the space is designed as a simple building, with an area of 1200 square meters. The design of spatial layout is to provide a convenient and comfortable environment for the elderly, while taking into account the behavioral needs of the elderly and service personnel, and the specific graphic design is shown in Fig. 3. 


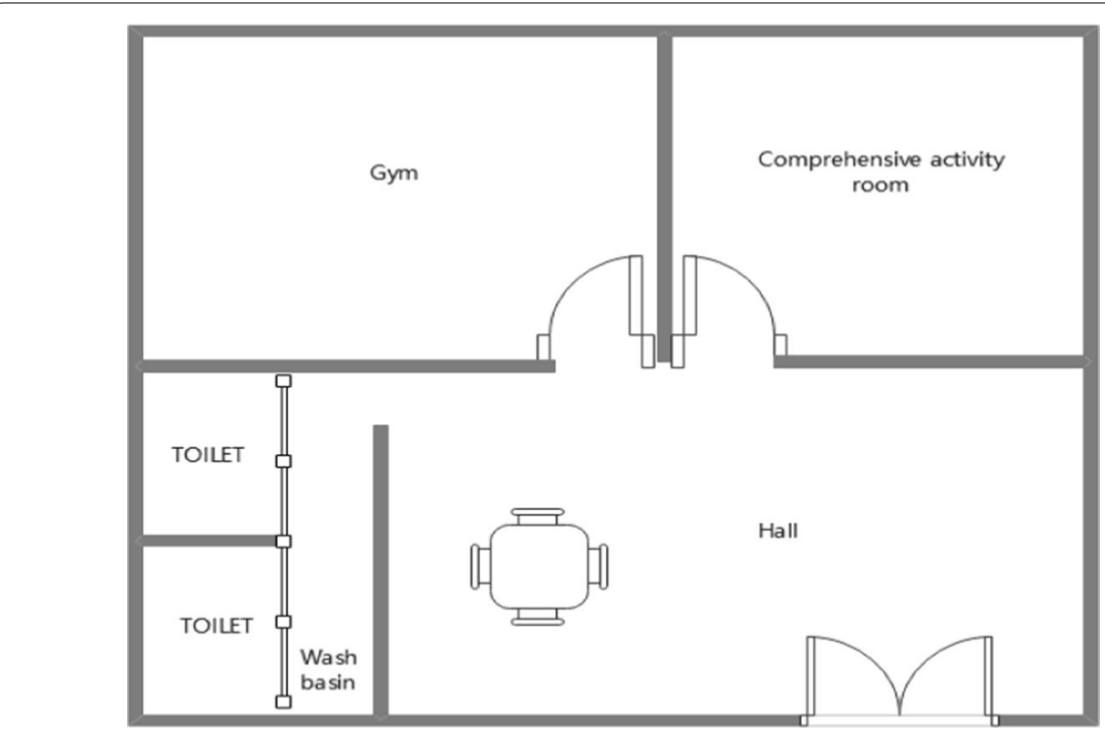

Fig. 3 Community space plan

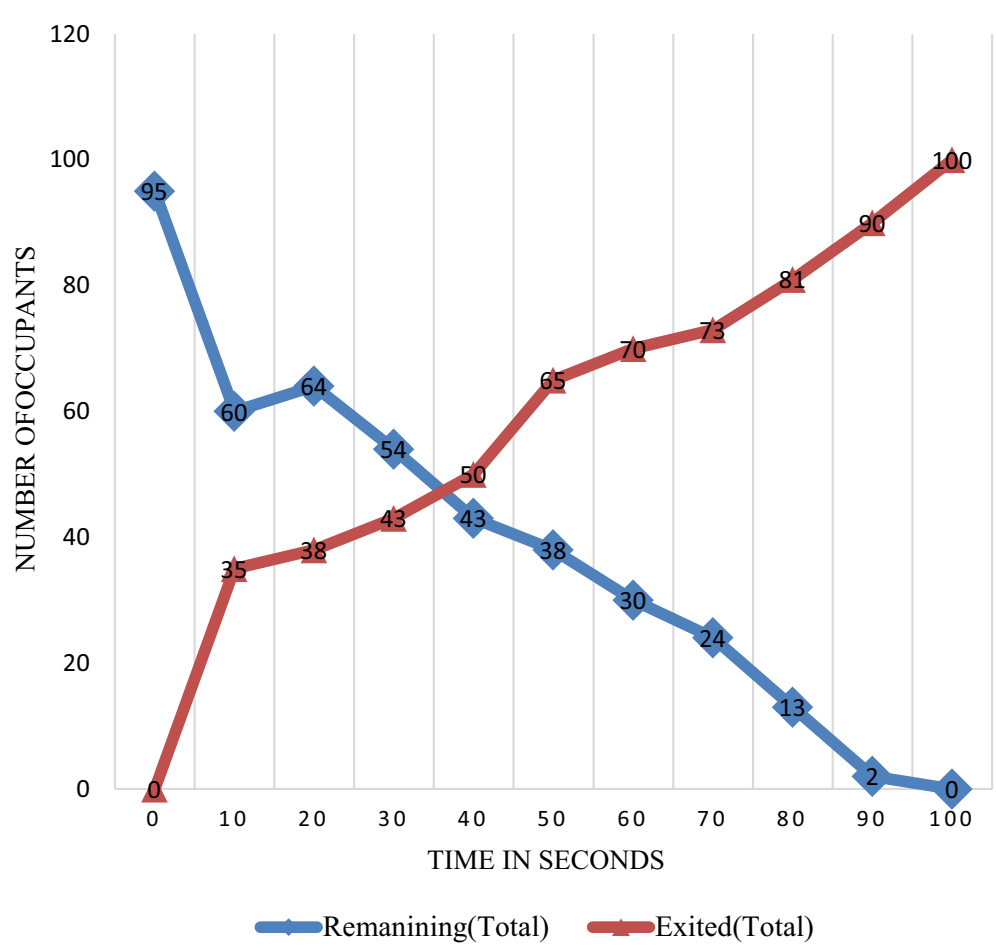

Fig. 4 Evacuation of personnel in each room and exit

\section{Results and discussion}

\subsection{Analysis of elderly people's evacuation in smart space positioning}

After specifying individual simulation parameters, such as the number of elderly people evacuated, the shoulder width of each elderly person, horizontal movement speed, and speed walking on the steps, choose the appropriate evacuation route (Fig. 4). The 


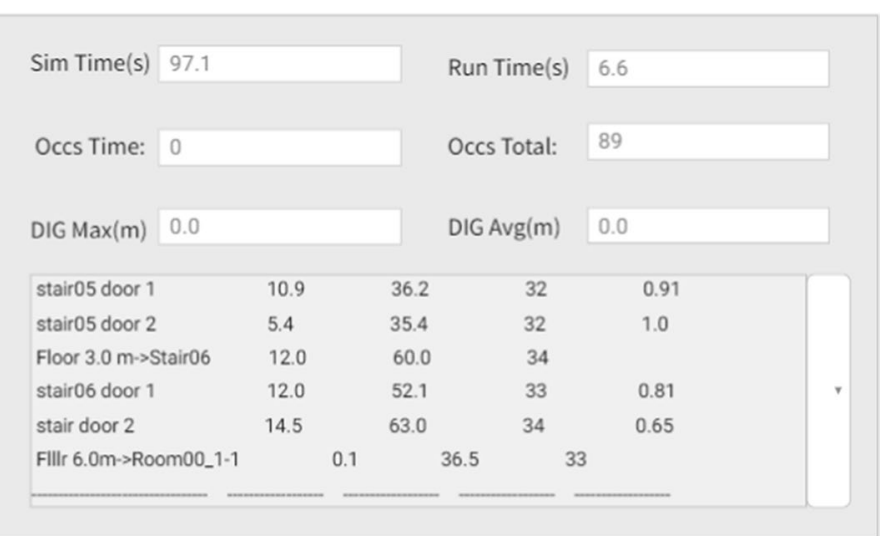

Fig. 5 BIM-based evacuation results for elderly in smart spaces

Table 1 Evacuation of personnel in each room and exit

\begin{tabular}{lll}
\hline Time in number of seconds occupants & Exit type & \\
\cline { 2 - 3 } & Remaining (total) & Exited (total) \\
\hline 0 & 95 & 0 \\
10 & 60 & 35 \\
20 & 64 & 38 \\
30 & 54 & 43 \\
40 & 43 & 50 \\
50 & 38 & 65 \\
60 & 30 & 70 \\
70 & 24 & 73 \\
80 & 13 & 81 \\
90 & 2 & 90 \\
100 & 0 & 100 \\
\hline
\end{tabular}

Table 2 Changes in the flow of people at each stairway and door

\begin{tabular}{|c|c|c|c|c|c|c|}
\hline \multirow{2}{*}{$\begin{array}{l}\text { Time in } \\
\text { seconds } \\
\text { flow rate }\end{array}$} & \multicolumn{6}{|l|}{ Exit } \\
\hline & $\begin{array}{l}\text { Stair05 } \\
\text { door } 1\end{array}$ & $\begin{array}{l}\text { Stair05 } \\
\text { door } 2\end{array}$ & $\begin{array}{l}\text { Stair06 } \\
\text { door } 1\end{array}$ & $\begin{array}{l}\text { Stair06 } \\
\text { door } 2\end{array}$ & $\begin{array}{l}\text { Stair07 } \\
\text { door } 1\end{array}$ & Stair07 door 2 \\
\hline 0 & 0 & 0 & 0 & 0 & 0 & 0 \\
\hline 10 & 1.5 & 1.9 & 1.6 & 1.2 & 1.2 & 0.5 \\
\hline 20 & 3.3 & 1.6 & 1.7 & 2.3 & 1.4 & 0.6 \\
\hline 30 & 2.4 & 1.7 & 1.9 & 2.4 & 1.3 & 0.8 \\
\hline 40 & 2.1 & 1.9 & 1.5 & 2.5 & 1.4 & 1.4 \\
\hline 50 & 1.0 & 1.3 & 1.4 & 0 & 0 & 1.1 \\
\hline
\end{tabular}

simulation results are shown in Fig. 5. The total evacuation time for 95 elderly people is $91.8 \mathrm{~s}$. Among them, the number of people evacuating from safe exits showed an upward trend with time, as shown in Table 1 and Fig. 4. The number of evacuees remain in the building [20]. 


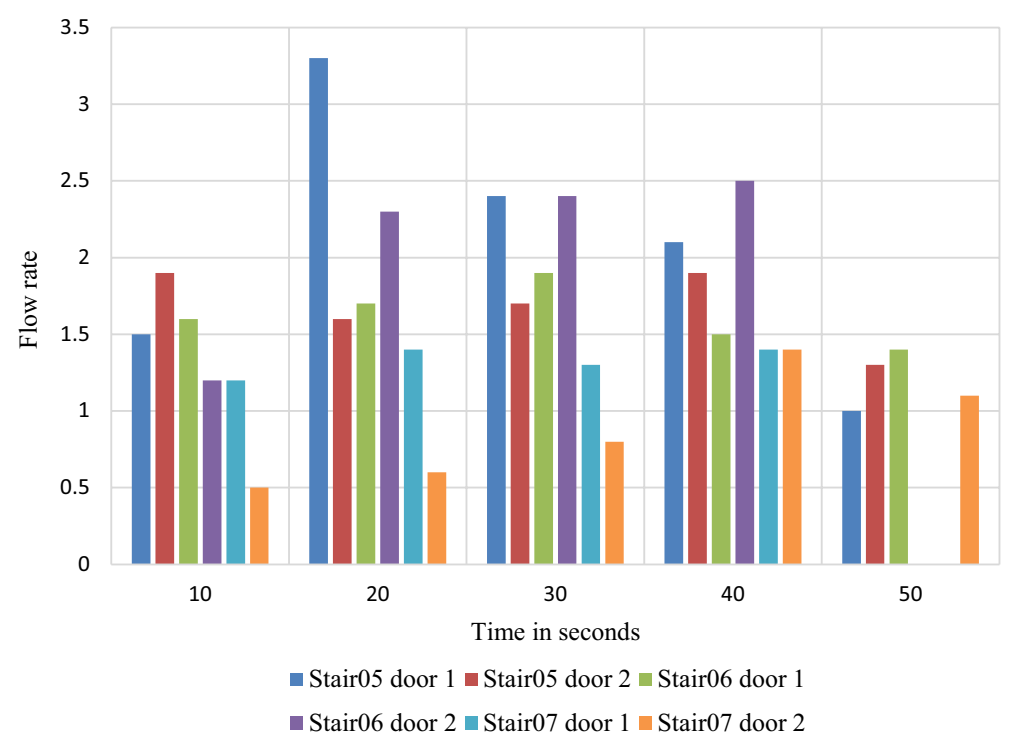

Fig. 6 Changes in the flow of people at each stairway and door

Table 2 and Fig. 6 show the flow of people at each stairway and doorway. Among them, the flow rate of Floor0. 0-Door3 reaches the highest at $12.47 \mathrm{~s}$, which is $3.11 \mathrm{pers} / \mathrm{s}$. /s, because Floor0. 0-Door3 is the only evacuation exit of the whole building on the first floor, and the first floor balcony is fully open. The model is set to reach the safe area as long as it reaches the first floor balcony safely.

\subsection{Analysis of positioning results of spatial positioning system}

According to the form of the above set of positioning system commands, a serial communication protocol is designed, and a CLocationEngine location engine class is designed. Communication protocols and engine categories can be easily ported to mobile targets in location detection systems such as location detection and monitoring services [21, 22].

In the position detection experiment, the CC2430 node was used as a gateway to connect with the computer to form a coordinated entrance. Eight CC2430 nodes are reference nodes, and one CC2431 node is a blind node for detecting moving targets. During the placement test, the reference node and the blind node are approximately one off the ground. As long as the CC2431 accessory engine can only be installed on a horizontal plane, the knuckles should be kept on the same horizontal plane as much as possible. The experiment is divided into two groups. Experiment 1 was conducted on the top platform of the experiment building. The reference nodes are arranged in a $10 \mathrm{~m}$ square, and the blind nodes are placed in different test positions. Since the installation result of the engine CC2431 has an analysis of $0.25 \mathrm{~m}$ and there is a reduction result, the installation result is a limited combination of coordinate $X$ and $Y$ data close to the actual position. Figure 7 shows the results of the placement experiment, where blue is the location of the reference node, sky is the location of the blind node, and yellow is the estimated location of the blind node. The $x$-, $y$-axis and error unit are $\mathrm{m}$. From the appearance, the absolute 


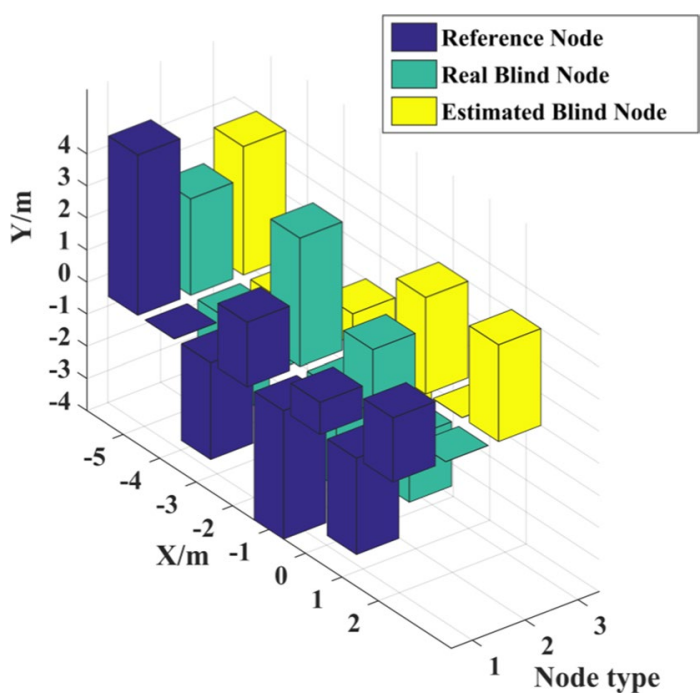

Fig. 7 Experiment 1 positioning error

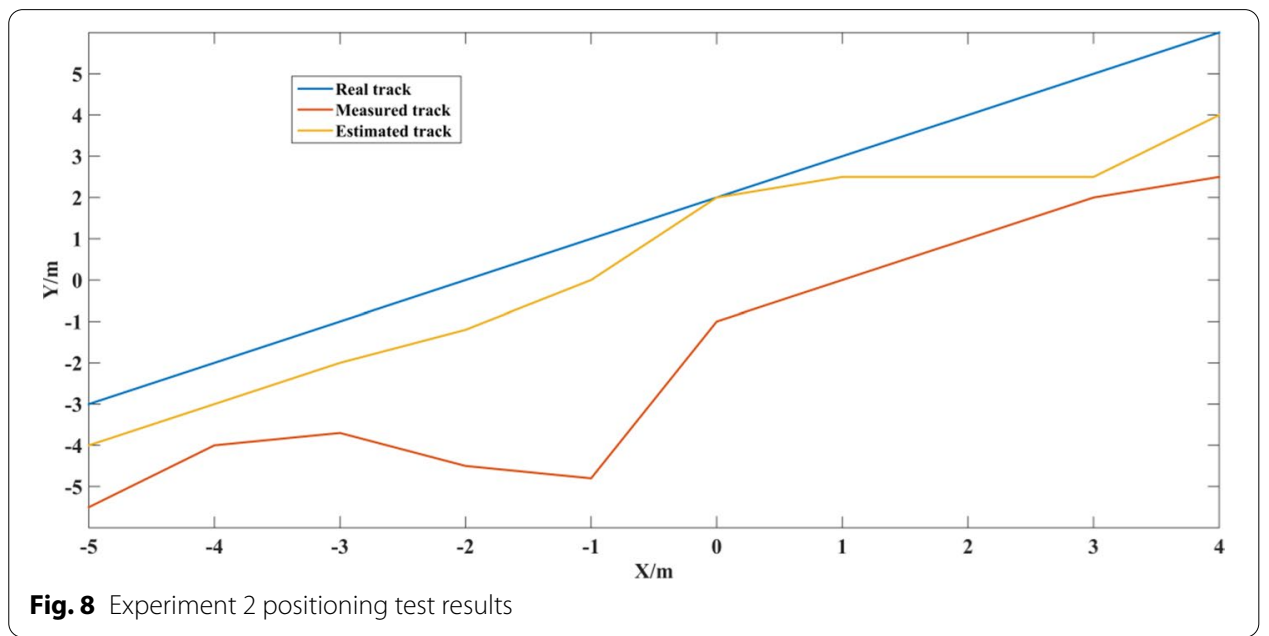

position error is less than $3 \mathrm{~m}$, and the positioning accuracy is better than the nominal accuracy position [23].

Experiment 2 was conducted in the experiment building. Place the blind node on the mobile robot platform and check whether the robot platform moves in the specified direction by remote control. It should be checked every time it moves about $0.5 \mathrm{~m}$. The results of the layout test are shown in Fig. 8. The blue curve is the actual trajectory, the red curve is the measurement trajectory, and the yellow curve is the Kalman filter trajectory estimation [24]. Due to the influence of the environment on the building, the detection error is slightly larger than that of the open environment, but Kalman filtering can still obtain a better estimate of the trajectory, reflecting the change of the actual moving target movement position. The placement error is less than $1.5 \mathrm{~m}$.

Experimental results show that the installation accuracy of the system in an open environment is good, and the installation error has increased the internal spatial structure, 
but the appropriate filtering algorithm may still have better estimation accuracy [25]. When applying a positioning system, some systems pre-determine parameters such as line loss indicators through experiments. In order to adapt to changes in the environment, evaluating and adjusting real-time positioning system parameters to improve positioning accuracy require further investigation [26].

\subsection{Determination of BIM CMM weight}

\section{Determination of BIM CMM score sheet}

The national BIM standard (nbims) of the USA provides a set of quantifiable BIM evaluation system centered on the exchange and use of project life cycle information, called BIM capability maturity model (BIM CMM). This maturity model is a quantitative evaluation of the BIM method and process of 11 elements, and each element is divided into ten levels of different maturity, of which 1 represents the most immature and 10 represents the most mature.

After the above-mentioned score table is used, the weight of CMM should be determined. BIM CMM score table is shown in Table 3 and Fig. 9.

For example, the highest score of data richness of the first element is 8.4 and the lowest score is 0.84 . When the data richness is at level 5 , the score of this element is 4.2.

\section{BIM CMM score sheet example.}

When we select the maturity level of 11 elements of a certain evaluated object, we can find out the corresponding scores from the above scoring table, and then, we can get the BIM score of this object after accumulation.

As shown in Table 4, we select the maturity level of 11 elements, respectively.

In this way, the score of the evaluation object is 19.2. According to the regulations of nbims, the minimum standard of BIM is 40 points, that is, this example does not meet the minimum standard of BIM. 50 points are BIM certification, 70 points silver medal BIM, 80 points gold BIM, and 90 points platinum BIM. This case is 30.9 points short of passing BIM certification.

\subsection{Analysis of experimental results of intelligent pension space positioning design based on BIM technology}

1. Reference Node Sensor Data Test

It can be seen from Fig. 10 that by comparing the sensor data displayed on the monitoring software with the field measurement data, the actual error is less than $10 \%$. The test results show that the reference node can realize the data acquisition and data transmission of various sensors.

2. System positioning effect test 


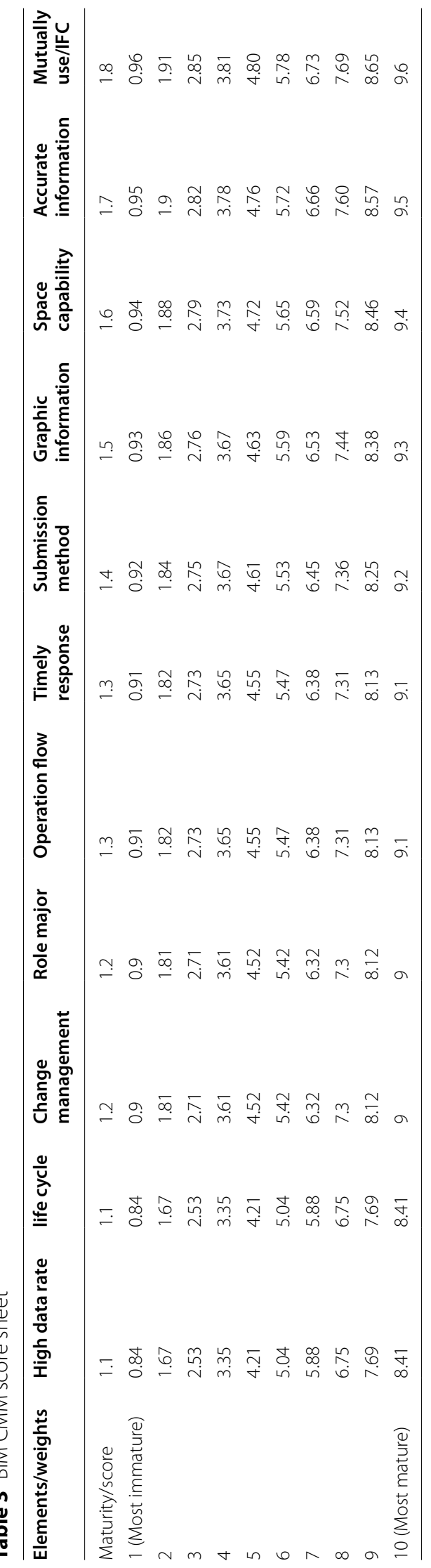




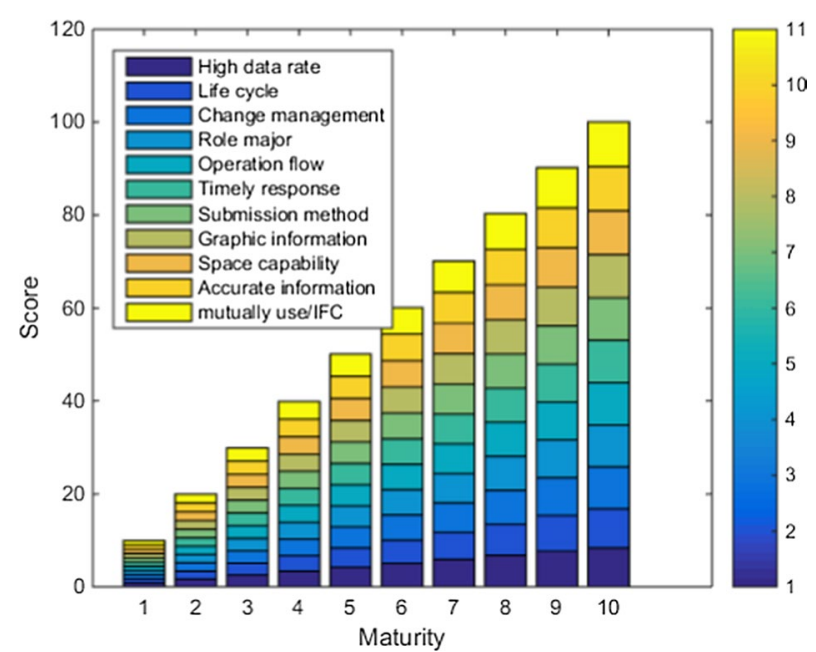

Fig. 9 BIM CMM score sheet

Table 4. Eleven maturity levels of elements

\begin{tabular}{lll}
\hline Serial number & Essential factor & $\begin{array}{c}\text { Maturity } \\
\text { level }\end{array}$ \\
\hline 1 & Data richness & 2 \\
2 & Life cycle & 1 \\
3 & Change management & 2 \\
4 & Role or profession & 3 \\
5 & Operation flow & 1 \\
6 & Timeliness/response & 1 \\
7 & Submission method & 3 \\
8 & Graphic information & 3 \\
9 & Space capability & 1 \\
10 & Information accuracy & 2 \\
11 & Interoperability/IFC support & 2 \\
\hline
\end{tabular}

The intelligent pension space designed in this paper has been tested in the field. The distance between reference nodes is $5 \mathrm{~m}$. The mobile nodes can move freely in the area surrounded by the reference nodes. Through 20 measurements of mobile nodes at different positions, the measurement results are shown in Fig. 11.

According to the measured results of Table 5, when the reference node spacing is $5 \mathrm{~m}$, the positioning accuracy of most location points in the effective positioning area can reach less than $1 \mathrm{~m}$, which basically meets the positioning requirements of intelligent pension space. System positioning for the elderly can achieve good results, effectively reduce risks, and meet the requirements of intelligent elderly care space.

\section{Conclusions}

This article analyzes the current status and trends of China's aging population and elaborates the number of problematic population in China's elderly care. Comparing the status quo of institutional care, home care and community care in China, this paper uses the PEST method to analyze and research the needs of smart community 

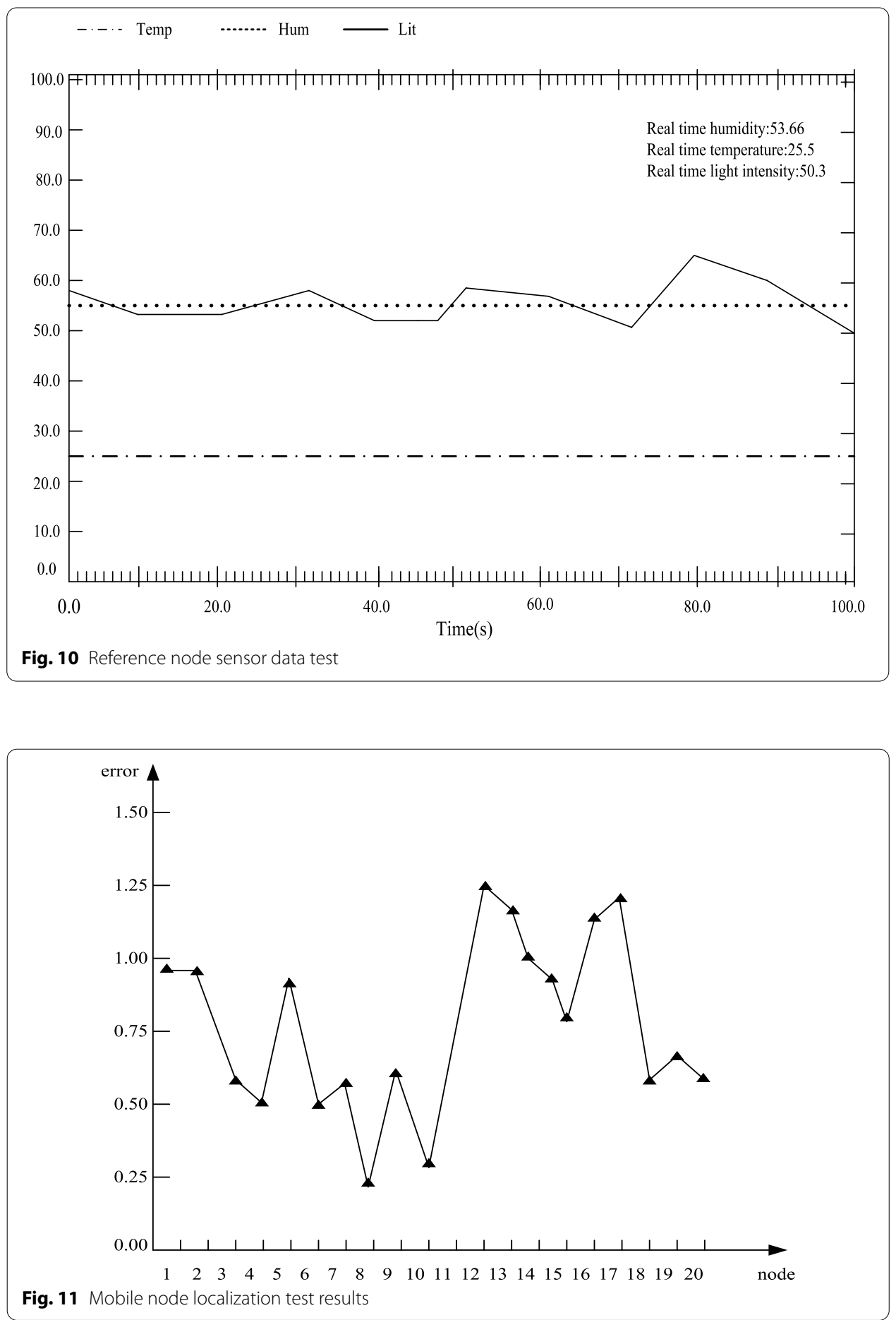

Table 5 Mobile node localization test results

\begin{tabular}{lllllllllll}
\hline Time node & 1 & 2 & 3 & 4 & 5 & 6 & 7 & 8 & 9 & 10 \\
Error value & 0.98 & 0.97 & 0.58 & 0.50 & 0.89 & 0.51 & 0.62 & 0.24 & 0.61 & 0.32 \\
Time node & 11 & 12 & 13 & 14 & 15 & 16 & 17 & 18 & 19 & 20 \\
Error value & 1.25 & 1.23 & 1.01 & 0.99 & 0.76 & 1.18 & 1.22 & 0.66 & 0.71 & 0.65 \\
\hline
\end{tabular}


care, and expounds the BIM theory related to the care of the elderly, and improves and perfects the community care. Based on the quality of life of the elderly, the normal psychological characteristics of the elderly are summarized, and the factors that affect the quality of the elderly are analyzed and manufactured. The system that affects the quality of old-age care in smart elderly communities is divided into two levels: standard level and factor level. The criterion level includes four indicators, and the factor level includes 20 influencing factors. The structural entropy weight method is adopted: Through comparison, the weight of the influencing factors is clarified, and the TOPSIS evaluation method of the impact of BIM on the quality of care of the elderly in the smart community is clarified. With the help of wireless communication technology, the establishment of intelligent pension community and the development of intelligent pension community are realized. In previous studies, the positioning design of the intelligent elderly care space is not perfect, which has affected the traditional home care. This article focuses on the repositioning design of the intelligent elderly care space based on the above two issues.

This article divides the advanced management units of the intelligent community into: intelligent elderly units, intelligent medical service units, functional units, intelligent communities, and intelligent living environment units for the smart retirement community pension quality evaluation system. At the same time, based on shared management a public pension management platform based on BIM was constructed. The platform includes data acquisition layer, data transmission layer, public platform layer, and integrated application layer. By combining data acquisition with wireless communications, combined with case analysis, it elaborated the application and value of BIM in the smart community pension. Introduce BIM model in Pathfinder evacuation software to simulate the evacuation and room layout of the elderly in the community elderly activity center, and optimize the flow control and space utilization. Finally, the TOPSIS method was used to evaluate the impact of BIM on the quality of care for the elderly in smart communities. We demonstrated the impact of BIM on improving the quality of service for the elderly in smart communities, analyzed the relative proximity of each factor system to have a corresponding impact, and found that BIM has a particularly significant impact on the living environment of the elderly.

This article discusses the social problem of "difficult pension," develops BIM-based technology, access to wireless communications technology, and implements an intelligent pension system. In order to provide site-based information services and effective surveys, the service model of pension institutions has important significance and wide scope.

\section{Authors' contributions}

All authors take part in the discussion of the work described in this paper. Both authors read and approved the final manuscript.

\section{Funding}

This research was funded by "The ministry of Education humanities and social sciences research project" project approval number 20YJCZH218" under healthy Chinese perspective integrate into the intelligent elderly housing space planning design research. 


\section{Declarations}

\section{Competing interests}

There are no potential competing interests in our paper. And all authors have seen the manuscript and approved to submit to your journal. We confirm that the content of the manuscript has not been published or submitted for publication elsewhere.

\section{Author details}

${ }^{1}$ School of Environmental Design, Wenzhou Business College, Wenzhou, Zhejiang Province, China. ${ }^{2}$ School of Management, China West Normal University, Nanchong 637002, Sichuan, China.

Received: 9 October 2020 Accepted: 24 June 2021

Published online: 07 July 2021

\section{References}

1. O.O. Akinade, L.O. Oyedele, S.O. Ajayi et al., Designing out construction waste using BIM technology: Stakeholders'expectations for industry deployment. J. Clean. Prod. 180(APR. 10), 375-385 (2018)

2. C. Hao, Analysis and research on information design of the smart community pension service. Academia $\mathbf{0 0 8}$, 268-280 (2018)

3. J. Hoque, M.M. Konai, S.S. Sequeira et al., Antibacterial and antibiofilm activity of cationic small molecules with spatial positioning of hydrophobicity: an in vitro and in vivo evaluation. J. Med. Chem. 59(23), 10750 (2016)

4. L. Zhiyang, Z. Tianqin, S. Zhixin, Application research of BIM technology in cost management. Eng. Constr. Des. 000(011), 138-141 (2015)

5. F. Haitao, Application of BIM technology in HVAC engineering. Intell. Build. City Inf. 000(012), 89-91 (2015)

6. B.M. Kefford, B. Ballinger, D.R. Schmeda-Lopez et al., The early retirement challenge for fossil fuel power plants in deep decarbonisation scenarios. Energy Policy 119(AUG.), 294-306 (2018)

7. W. Dongmei, An analysis of the development path of smart pension industry in Hebei Province. J. Baoding Univ. 031(004), 43-49 (2018)

8. Y. Xiaoyan, Z. Yinxia, Research on the development and practice of smart pension policy in China. J. Xi'an Univ. Archit. Technol. Soc. Sci. Ed. 037(005), 42-48 (2018)

9. M. Xianpo, Discussion on the model of embedded medical care combined with smart elderly care-taking Dongying Qinxiangyuan Pension Service Co., Ltd. as an example. J. Shengli Oilfield Party Sch. 029(005), 85-88 (2016)

10. Y. Qing, Z. Zhengqiang, Application status and potential development research of smart pension platform-taking XX city of Shandong as an example. Foreign Trade 008(122-123), 126 (2018)

11. E.S. Craig, M. Yuhasz, A. Shah et al., Simulated surgery and cutting guides enhance spatial positioning in free fibular mandibular reconstruction. Microsurgery 35(1), 29-33 (2015)

12. J.A. Teichroeb, M.M.J. White, C.A. Chapman, Vervet (Chlorocebus pygerythrus) intragroup spatial positioning: dominants trade-off predation risk for increased food acquisition. Int. J. Primatol. 36(1), 154-176 (2015)

13. M.G. Hoang, B. Denis, J. Härri et al., Breaking the gridlock of spatial correlations in GPS-aided IEEE 80211 p-based cooperative positioning. IEEE Trans. Veh. Technol. 65(12), 9554-9569 (2016)

14. Li. Kun, The application study of BIM technology in the structure design of subway station\%BIM technology in subway station structure design. J. Railw. Eng. Soc. 032(002), 103-108 (2015)

15. J. Chun, Ma. Jinhui, F. Tianen et al., RSSI fingerprint interpolation method for Bluetooth indoor positioning based on spatiotemporal similarity model. Sci. Technol. Eng. 016(028), 264-268 (2016)

16. A.E. Rothberg, J.B. Halter, Obesity and diabetes in an aging population. Clin. Geriatr. Med. 31(1), 1-15 (2015)

17. M.M. Baig, H. Gholamhosseini, M.J. Connolly, Mobile healthcare applications: system design review, critical issues and challenges. Australas. Phys. Eng. Sci. Med. 38(1), 23-38 (2015)

18. W. Bi, G.C. Dandy, H.R. Maier, Improved genetic algorithm optimization of water distribution system design by incorporating domain knowledge. Environ. Modell. Softw. 69(10), 370-381 (2015)

19. T.S. Rappaport, G.R. Maccartney, M.K. Samimi et al., Wideband millimeter-wave propagation measurements and channel models for future wireless communication system design. IEEE Trans. Commun. 63(9), 3029-3056 (2015)

20. L. Chao, Z. Tianyi, Z. Jili et al., Design and application analysis of building thermal engineering system and HVAC system based on building information model. HVAC 046(003), 27-32 (2016)

21. S. Black, E. De Gregorio, R. Rappuoli, Developing vaccines for an aging population. Sci. Transl. Med. 7(281), 281 ps8 (2015)

22. D.W. Elmendorf, L.M. Sheiner, Federal budget policy with an aging population and persistendy low interest rates. J. Econ. Perspect. 31(3), 175-194 (2017)

23. Z. Weibin, W. Shuwen, Construction of Japan's elderly population nursing and welfare system and reference to China. Mod. Jpn. Econ. 000(003), 71-82 (2015)

24. T. Yuehong, Z. Xianglian, Research on population aging, delayed retirement and financial sustainability of basic pensions. Popul. Econ. 000(001), 39-49 (2016)

25. Z. Wu, J. Guo, Y. Huang et al., Diabetes mellitus in patients with pulmonary tuberculosis in an aging population in Shanghai, China: Prevalence, Clinical characteristics and Outcomes. J. Diabetes Complic. 30(2), $237-241$ (2015)

26. C. Fan, C. Lingyun, Analysis of the impact of population aging on China's import trade-an empirical study based on static and dynamic spatial panel models. Int. Econ. Trade Res. 032(012), 37-48 (2016)

\section{Publisher's Note}

Springer Nature remains neutral with regard to jurisdictional claims in published maps and institutional affiliations. 